\title{
SITE SUITABILITY ANALYSIS FOR BEEKEEPING VIA ANALYTHICAL HYREARCHY PROCESS, KONYA EXAMPLE
}

\author{
F.Sar1 ${ }^{a}$, D.A.Ceylan ${ }^{\mathrm{b}}$ \\ ${ }^{a}$ SU, Cumra School of Applied Sciences, Konya, Turkey - fatihsari@ selcuk.edu.tr \\ ${ }^{b}$ SU, Cumra Vocational School Konya, Turkey - daliceylan@ @elcuk.edu.tr
}

KEY WORDS: Multi Decision Criteria, Geographical Information Systems, Beekeeping, Site Suitability

\begin{abstract}
:
Over the past decade, the importance of the beekeeping activities has been emphasized in the field of biodiversity, ecosystems, agriculture and human health. Thus, efficient management and deciding correct beekeeping activities seems essential to maintain and improve productivity and efficiency. Due to this importance, considering the economic contributions to the rural area, the need for suitability analysis concept has been revealed. At this point, Multi Criteria Decision Analysis (MCDA) and Geographical Information Systems (GIS) integration provides efficient solutions to the complex structure of decision- making process for beekeeping activities.

In this study, site suitability analysis via Analytical Hierarchy Process (AHP) was carried out for Konya city in Turkey. Slope, elevation, aspect, distance to water resources, roads and settlements, precipitation and flora criteria are included to determine suitability. The requirements, expectations and limitations of beekeeping activities are specified with the participation of experts and stakeholders. The final suitability map were validated with existing 117 beekeeping locations and Turkish Statistical Institute 2016 beekeeping statistics for Konya province.
\end{abstract}

\section{INTRODUCTION}

Turkey has considerable potential in beekeeping with her rich flora, proper ecological conditions and existence of colony. According to the 2015 beekeeping statistics, Turkey has a rapidly increasing honey production with 107.665 tons and 7.709.636 waxes count. However Turkish beekeeping sector has not utilized the rich natural resources sufficiently. Thus, management and monitoring beekeeping activities are being more important to provide efficient and sustainable productivity. Furthermore, determining suitable locations for beekeeping should be evaluated in the field of land use planning considering economical, ecological, environmental and social aspects. Because honeybees are the key pollinator of $33 \%$ of crop species, there is a high amount of invisible economic income that involved in agricultural activities (Oldroyd and Nanork, 2009; Maris et al., 2008).

Land Suitability Analysis (LSA) can be assessed on the basis of physical environmental, social and economic data (FAO, 1976; Jafari and Zaredar, 2010; Zhang et al., 2015). Land use should be planned to meet human needs and ensure the sustainability of ecosystems (Amiri and Shariff, 2012) and optimum use of the resources for sustainable land management by identifying the most appropriate future land planning according to the requirements and preferences (Ahamed et al., 2000; Collins et al., 2001; Malczewski, 2004; Zolekar and Bhagat, 2015).

Multi Criteria Decision Analysis (MCDA) techniques are widely used for LSA. MCDA of land suitability involves multiple criteria like elevation, slope, atmospheric conditions and land use, etc as well as environmental and socio-economic approaches to find best solutions within multiple alternatives (Wang et al., 1990; Joerin et al., 2001; Yu et al., 2011; Zolekar and Bhagat, 2015). One of the most applied MCDA approaches is the Analytical Hierarchy Process (AHP) which calculates the weights of criteria among the factors that affect the total suitability (Saaty, 1977, 1980, 1994, 2001; Saaty and Vargas, 1991). AHP refers to the applications which are used to determine the most suitable solutions to the real problems by providing a selection of different data clusters (Arentze and Timmermans, 2000) and calculates the weights associated with criteria via pairwise preference matrix where all criteria are compared against each other (Chen et al., 2010). The calculated weights represent the importance of criteria relatively which will contribute to the generation of suitability map.

In this study, weighting were calculated for each criterion in order to generate a suitability map for beekeeping in Konya. The AHP method was used to calculate weighting and ArcGIS software was used to generate a suitability map. The weights and importance of each criterion was specified by bee experts and specialists. 


\section{MATERIAL METHOD}

\subsection{Study Area}

Konya is one of the main centers of grain farming with its plain and large agricultural lands (Figure 1). According to the Turkish Statistical Institute, Konya has 18618142 decare for grain farming, 207665 decare for vegetable gardens and 412918 for fruits (apple, pear, cherry, plum, apricot, peach, almond, walnut), beverage and spices within total 19239667 decare arable lands. The forests are found mostly in the mountainous parts of the province and consist of Black Pine, Oak, Red Pine, Juniper, Cedar and Fir respectively. The naturally grown plants in region are Alcea pallida, Amaranthus retroflexus, Astragalus alepecuroides, Celosia cristata, Centaurea cyanus, Cirsium acarna, Cirsium arvense, Dianthus erinaceus bois var erinaceus, Echium italicum, Epilobium hirsutum, Euphorbia amygdaloides, Galanthus elvesii, Glaucium corniculatum, Heracleum platytaenium, Lamium amplexicaule, Malva sylvestris, Onapardum Illyricum, Pyracantha coccinea, Rhus typhina, Taraxacum serotinum, Trifolium purpureumlois var purpureum, Urtica dioica, Verbascum undulatum.

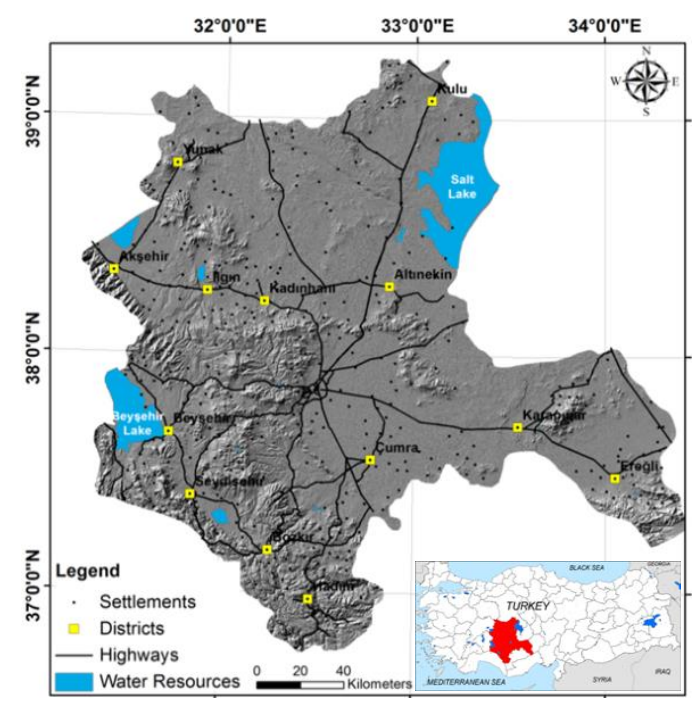

Figure 1. Study Area

\subsection{Criteria Selection}

The criteria selection reflects the requirements, expectations and restrictions of beekeeping activities. Beekeeping has some assumptions and expectations when locating waxes in the field of topographic, environmental, meteorological and economical perspective. Advanced beekeeping activities require being in ideal interval for each criterion.

Aspect: Aspect criterion is included to be able to determine the direction effect. Considering wax locations and directions, beekeepers prefer South, South-East and South-West directions when locating waxes to benefit from the daylight. These directions are also important to protect waxes from north winds.

Elevation: Elevation criterion related to flora and defines seasonal start of the beekeeping activities. For study area, honey production yield and efficiency is decreasing above 2000 meter due to the meteorological conditions and winds.
Flora: Flora of the study area defines the honey production quality and quantity addition to honey type. Thus, the most important criterion should be flora and weighted higher values than others. Forests and natural plant areas are preferred to benefit from plant diversity to provide organic honey production. Urban settlements and industrial areas are not included to avoid disadvantages and effects of urbanization on honey production. Although agricultural lands have an important role on honey production, pesticide using is one of the main risks for bees. Thus, agricultural lands are weighted as non-important.

Distance to Roads and Settlements: Beekeepers prefer to locate waxes outside of urban places and roads to decrease greenhouse gases, air and noise pollution, exhaust emissions, urban and industrial contaminants and human related factors. Thus, distance from settlements and distance from highways criteria are included in suitability analysis.

Distance to Waters: Water resources are important for bees to provide enough water that will be used for cooling the waxes and honey production. The city has average 1020 elevation above sea level and has water resources with 2127 square meters.

Slope: Similar to elevation, slope criterion has a close relationship with flora due to rapidly changing topography, meteorological conditions and directions.

Precipitation: Precipitation has a close relationship with flora and defines the characteristic features of study area. Precipitation expected to be between $1275 \mathrm{~mm}$ and $1800 \mathrm{~mm}$ annual rainfall (Maris et al., 2008) and related with elevation, flora and its flowering season.

\subsection{Analytical Hierarchy Process (AHP)}

The procedure outlined by Saaty $(1977,1980)$ scales the importance of each criterion, from 1 to 9 relatively (Table 1). The pairwise matrix includes the scales and determines the importance of criteria (Table 2).

\begin{tabular}{ccccc}
\hline $\mathbf{1}$ & $\mathbf{3}$ & $\mathbf{5}$ & $\mathbf{7}$ & $\mathbf{9}$ \\
\hline Equal & Moderately & Strongly & Very & Extremely \\
\hline
\end{tabular}

Table 1 . Saaty 1 to 9 Scale

\begin{tabular}{cccccc}
\hline $\boldsymbol{A}$ & $\boldsymbol{C 1}$ & $\boldsymbol{C 2}$ & $\boldsymbol{C 3}$ & $\ldots$ & $\boldsymbol{C n}$ \\
\hline $\boldsymbol{C 1}$ & $a_{11}$ & $a_{12}$ & $a_{13}$ & $\ldots$ & $a_{1 n}$ \\
$\boldsymbol{C 2}$ & $a_{21}$ & $a_{22}$ & $a_{23}$ & $\ldots$ & $a_{2 n}$ \\
$\ldots$ & $\ldots$ & $\ldots$ & $\ldots$ & $\ldots$ & $\ldots$ \\
$\boldsymbol{C n}$ & $a_{n 1}$ & $a_{n 2}$ & $a_{n 3}$ & $\ldots$ & $a_{n n}$ \\
\hline
\end{tabular}

Table 2. Pairwise comparison matrix

The pairwise comparison square matrix is defined for maincriteria and sub-criteria to determine the weights. The diagonal element of the comparison matrix is 1 . Each element of the 
comparison matrix is divided by the sum of its own column sum to generate a normalized matrix with Formula 1.

$$
a_{i j}^{1}=\frac{a_{i j}}{\sum_{i=1}^{n} a_{i j}}
$$

Each column of the normalized matrix sum is equal to 1 . Then, each row sum of the normalized matrix is divided by the matrix order. The average of the sum represents the weights of each criterion in pairwise comparison matrix (Formula 2).

$w_{i}=\left(\frac{1}{n}\right) \sum_{i=1}^{n} a_{i j}^{\prime},(i, j=1,2,3, \ldots, n)$

The consistency of the pairwise comparison matrix must be calculated to decide the criteria, comparisons are consistent or not. The assigned preference values are synthesized to determine a ranking of the relevant factors in terms of a numerical value which is equivalent to the weights of each parameter. Therefore, the eigenvalues and eigenvectors of the square pairwise comparison matrix, revealing important details about patterns in the data matrix are calculated (Saaty and Vargas 1991).Consistency Index (CI) is one of the methods to define the consistency coefficient of the pairwise comparison matrix. CI is calculated with Formula 3 (Saaty, 1994).

$C I=\frac{\lambda_{\max }-n}{n-1}$

Calculating consistency index depends on the $\lambda \max$ (eigen value) value with Formula 4 (Saaty, 1994).

$\lambda_{\max }=\frac{1}{n} \sum_{i=1}^{n}\left[\frac{\sum_{j=1}^{n} a_{i j} w_{j}}{w_{i}}\right]$

In addition to this, the Random Index (RI) value must be calculated to determine the consistency index.

After calculating the CI and RI, consistency ratio (CR) can be calculated with Formula 5. If CR exceeds 0.1, based on expert knowledge and experience, Saaty \& Vargas (1991) recommends a revision of the pairwise comparison matrix with different values (Saaty, 1980).

$C R=\frac{C I}{R I}$

\section{APPLICATION}

Each criterion is mapped and then reclassified with the ArcGIS software according to the defined classes which are illustrated in Figure 2. The layers and the classes are associated with the weights to generate the suitability map. In each figure, the suitability value is illustrated from highly suitable (green) to none suitable (red) relatively.

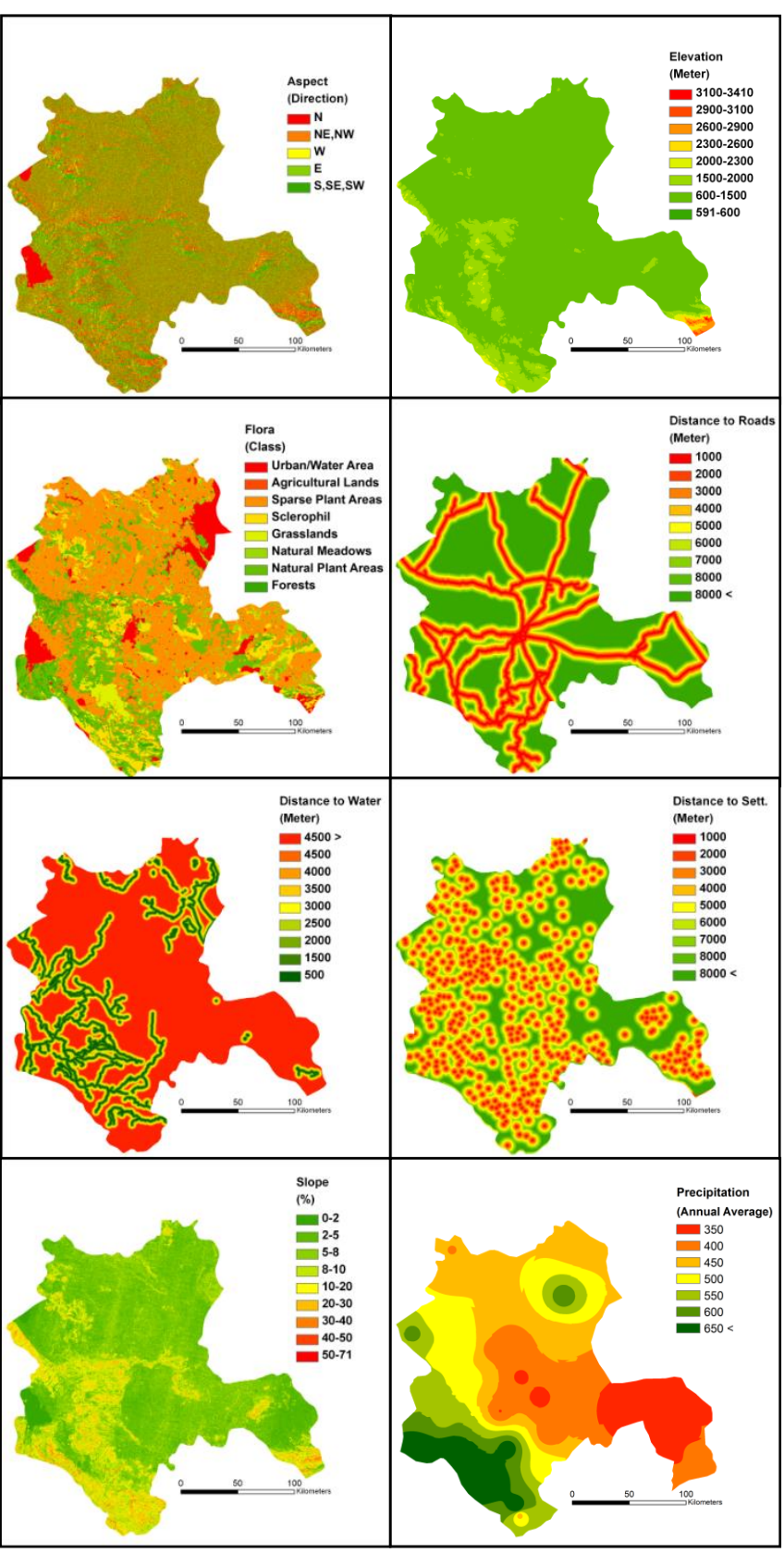

Figure 2. Criteria maps

Generating suitability maps require calculating the weights of each criterion to determine the importance of criteria to each other. AHP pairwise matrix is used to calculate the weights of criteria by using ranking values from 1-to 9 (Table 1).

In the first stage, criteria weights are calculated with a pairwise matrix via AHP by specifying the importance of each criterion to another. The sum of the weights must be equal to 1 . Due to the high importance of flora and distance to water resources criteria, the weights are calculated as $44 \%$ and $15 \%$ with a 0.081 consistency ratio value which means the weights are consistent. The calculated weights (Table 3) and pairwise comparison matrix is given in Table 2 . 


\begin{tabular}{lc}
\hline \multicolumn{1}{c}{ Criteria } & W \\
\hline Aspect & 0.120 \\
Elevation & 0.100 \\
Flora & 0.440 \\
Dist.Roads & 0.039 \\
Dist.Waters & 0.146 \\
Dist.Sett. & 0.033 \\
Slope & 0.044 \\
Precipitation & 0.076 \\
\hline
\end{tabular}

Table 3. AHP weights

\section{RESULTS}

The results indicate that $48 \%$ of the study area is assigned as suitable and $52 \%$ of the study area is not suitable according to the AHP calculation. As can be seen in Table 3, flora criterion have $44 \%$, distance to waters $14.60 \%$ and aspect have $10 \%$ weights in total weight ranking. It is possible to say that approximately $70 \%$ of suitability is defined by these classes. Because distance from settlements and distance from roads criteria doesn't have an effect on beekeeping suitability directly, these classes have $3 \%$ and $4 \%$ weights in total weight ranking. The total beekeeping suitability map is given in Figure 3.

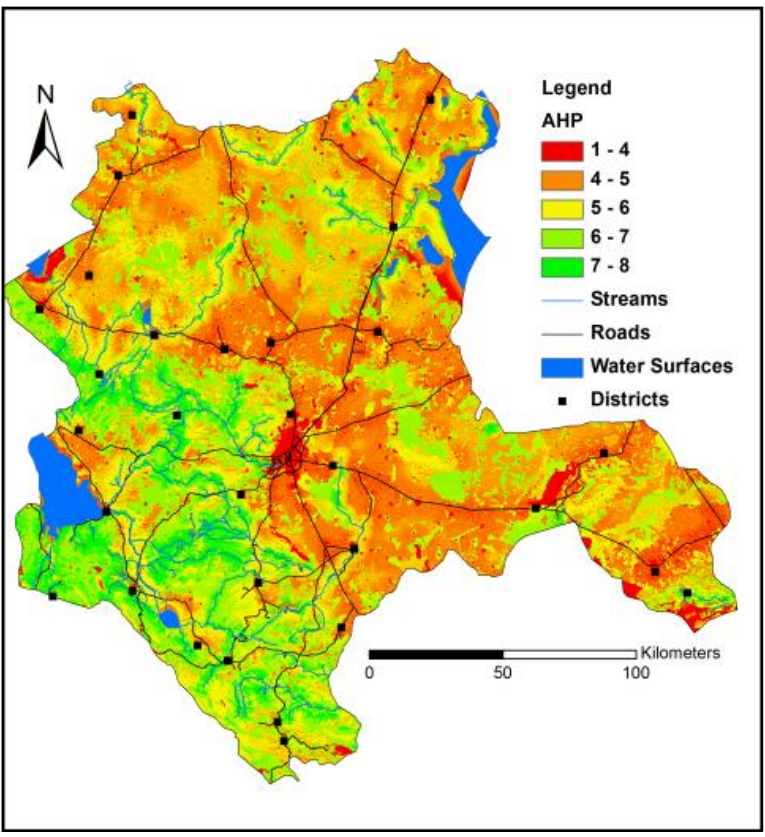

Figure 3. Suitability map

The effectiveness and reliability of the determined suitabilities can be verified in several ways such as considering existing beekeeping locations, evaluating with experts and testing suitable locations over the next year. The most reliable and rapid results can be obtained through a correlation analysis of the existing beekeeping statistics and determined suitability values. Thus, Turkish Statistical Institute 2015 apiculture statistics are used to calculate correlation. According to the statistics, total honey production, total waxes and total beekeepers counts are available at district level and Bozkır,
Hadim, Seydişehir, Beyşehir and Meram districts have highest honey production rate which are also overlapped with the suitability maps. The statistic thematic maps are given in Figure 4.

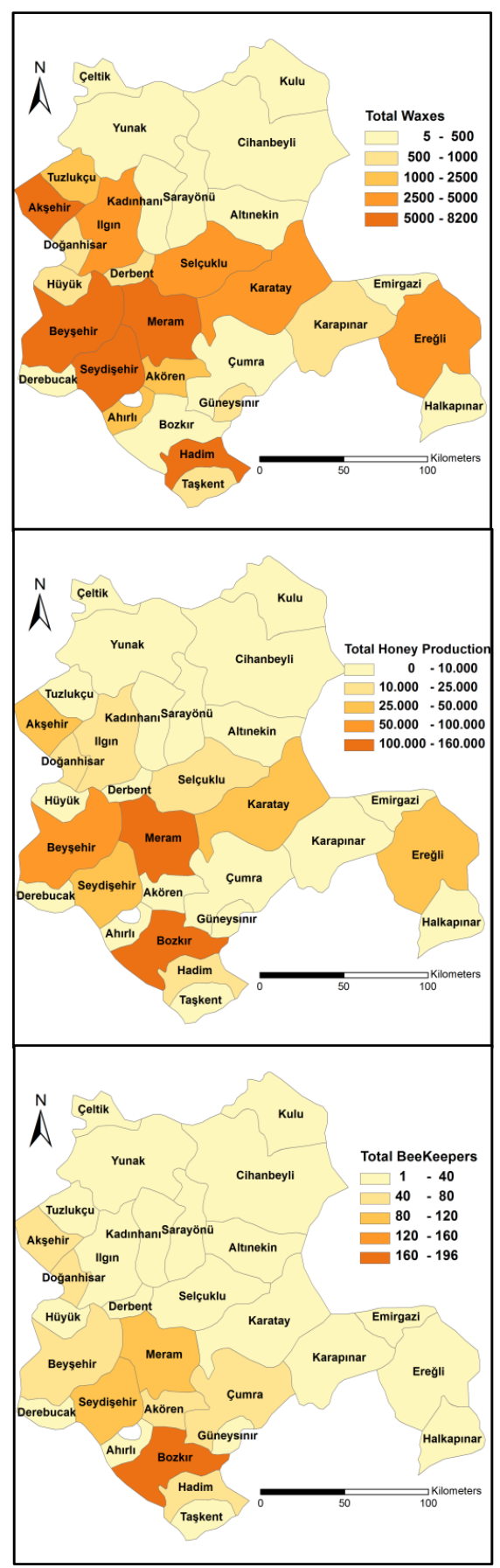

Figure 4. TUIK 2015 statistics for Konya

For the purpose of evaluating reliability and making a comparison, correlation of both AHP and correlation of suitability values and beekeeping statistics are determined. Total honey production, total beekeeper count and wax count values are involved in correlation analysis with AHP. For correlation analysis, 9, 8 and 7 values are converted to \% suitability rate for each district considering the area. For instance, 9,8 and 7 
rankings cover $70 \%$ of Bozkır district area in AHP. The detailed values are given in Table 4 .

\begin{tabular}{|c|c|c|c|c|}
\hline District & $\begin{array}{c}\text { Total } \\
\text { Beekeeper } \\
\text { (person) }\end{array}$ & $\begin{array}{c}\text { Total } \\
\text { Waxes } \\
\text { (number) }\end{array}$ & $\begin{array}{c}\text { Total } \\
\text { Honey } \\
\text { Production } \\
(\mathbf{k g})\end{array}$ & $\underset{\%}{\mathbf{A H P}}$ \\
\hline Bozkır & 196 & 148 & 160000 & 70 \\
\hline Meram & 96 & 7547 & 132125 & 70 \\
\hline Beyşehir & 77 & 6971 & 104565 & 58 \\
\hline Seydișehir & 87 & 8165 & 89815 & 63 \\
\hline Karatay & 21 & 3451 & 85246 & 10 \\
\hline Akșehir & 42 & 7953 & 75550 & 47 \\
\hline Ereğli & 30 & 4785 & 71100 & 20 \\
\hline Doğanhisar & 45 & 545 & 60000 & 60 \\
\hline Selçuklu & 24 & 3325 & 58000 & 30 \\
\hline Ilgin & 19 & 4149 & 54000 & 47 \\
\hline Hadim & 64 & 7319 & 35940 & 75 \\
\hline Çumra & 69 & 5 & 22000 & 12 \\
\hline Akören & 65 & 1213 & 20800 & 40 \\
\hline Derebucak & 35 & 231 & 15600 & 60 \\
\hline Ahırlı & 14 & 1076 & 13700 & 50 \\
\hline Tuzlukçu & 6 & 1023 & 10500 & 4 \\
\hline Karapınar & 6 & 913 & 8250 & 15 \\
\hline Güneysınır & 12 & 851 & 8200 & 28 \\
\hline Hüyük & 22 & 865 & 6525 & 10 \\
\hline Derbent & 15 & 700 & 6070 & 65 \\
\hline Kulu & 1 & 284 & 6020 & 8 \\
\hline Sarayönü & 4 & 365 & 5000 & 9 \\
\hline Altınekin & 4 & 210 & 2800 & 7 \\
\hline Yunak & 4 & 275 & 2750 & 7 \\
\hline Halkapınar & 10 & 355 & 2250 & 30 \\
\hline Cihanbeyli & 2 & 285 & 2160 & 7 \\
\hline Emirgazi & 2 & 155 & 1560 & 4 \\
\hline Taşkent & 9 & 562 & 1437 & 30 \\
\hline Kadınhanı & 1 & 240 & 1200 & 9 \\
\hline Çeltik & 1 & 90 & 0 & 2 \\
\hline
\end{tabular}

Table 4. AHP weights

According to the $r$ values of correlation analysis, there is a good correlation with $0.70 \mathrm{r}$ value between the total beekeeper count and calculated suitability values. The reason that total beekeeper count correlations are higher than others, the beekeepers must be registered to Republic of Turkey Ministry of Food, Agriculture and Livestock provincial directorates to be able to locate waxes. Thus, beekeeper counts represent the most real values. The correlation graphics are given in Figure 5.

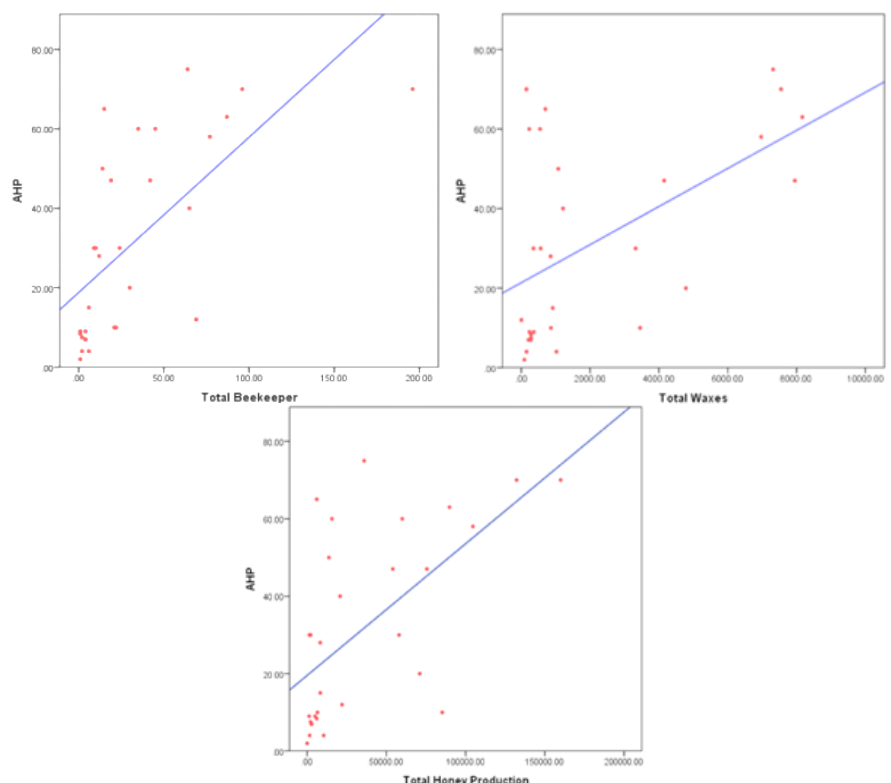

Figure 5. Correlation graphics $(r=0,66, r=0,54, r=0,61)$
As a different validation, for the purpose of determining the accuracy and reliability rate of these methods, existing beekeeper locations are retrieved from the Konya- Seydişehir, Beyşehir, Çumra, Hadim and Taşkent Directorate of Provincial Food Agriculture and Livestock. Existing beekeeper locations are recorded between May and September 2016 with their attribute data such as wax count, beekeeper name, address and honey type. In total, 117 existing beekeepers location coordinates are integrated to suitability maps to visualize the intersections. Distribution of the locations and intersection with the AHP suitability map are given in Figure 6.

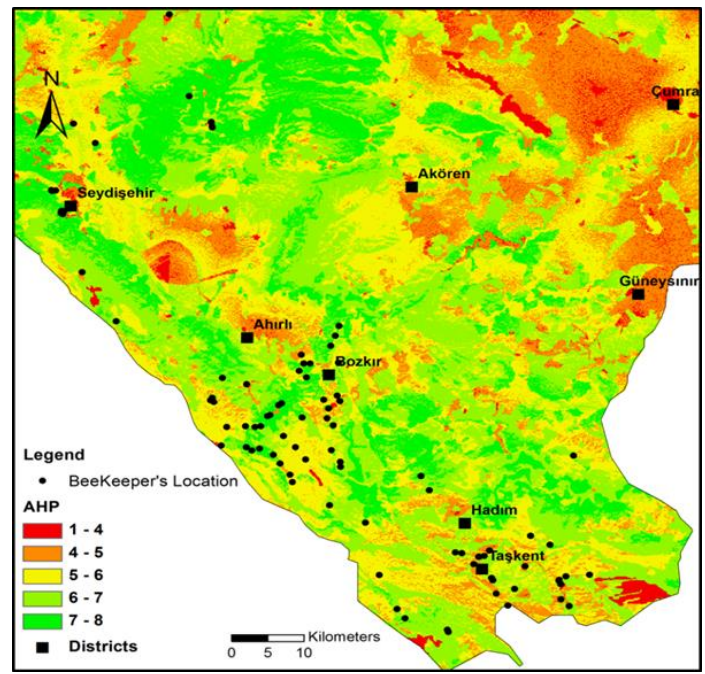

Figure 6. Existing beekeeper locations

The detailed view of existing beekeeper locations are given in Figure 7.

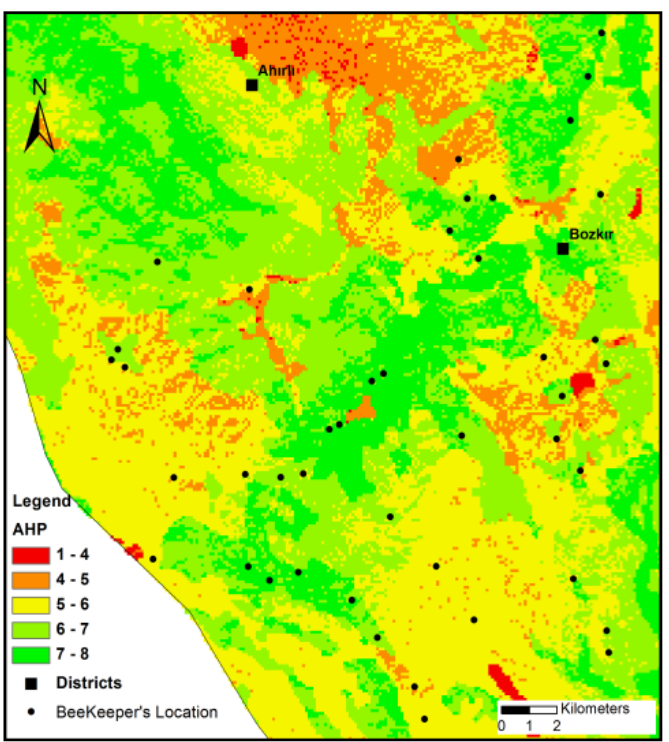




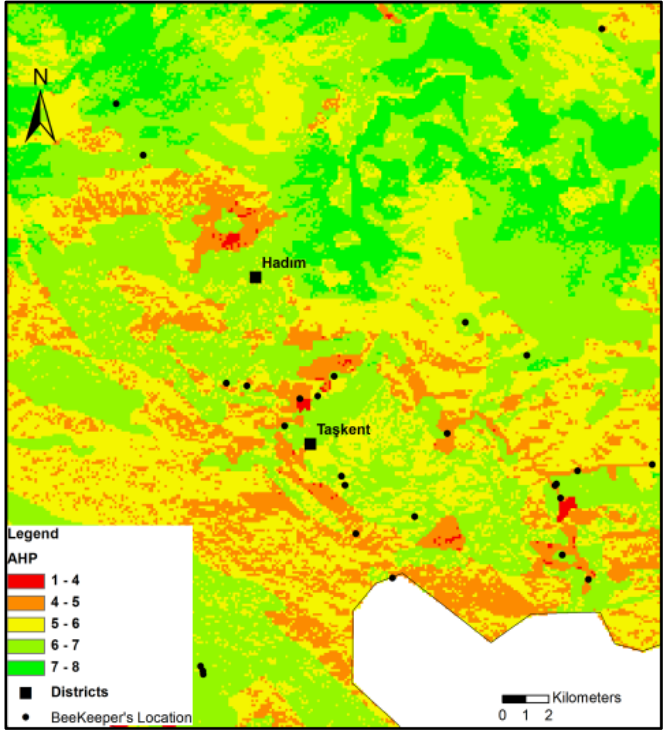

Figure 7. Existing bekeeper locations (Detailed view)

\section{DISCUSSION}

Although modeling bee behaviors is a very difficult process, the suitability determination and validations increase the reliability and applicability of suitability analysis via MCDA methods. The main stage of the suitability analysis is criteria selection according to the beekeeping requirements. It must be pointed out that beekeeping expert decisions have the largest contribution to suitability projects. Additional criteria such as meteorological conditions, wind directions, flowering, foraging area, electromagnetic fields and pesticide usage in agricultural lands can be involved in suitability to increase the accuracy. However, these criteria are unstable and difficult to monitor and update. Thus, the reliability of criteria is decreasing due to the lack of monitoring and registration systems which will guide to beekeepers for advanced beekeeping activities. Addition to this, because flowering and foraging area are time-depended criteria, mapping and illustrating these criteria have some difficulties due to the climatic, meteorological and topographic situations of beekeeping locations. Nevertheless, the results and validation of the suitability are quite satisfactory considering the intersection of existing locations with suitability maps and correlation analysis with beekeeping statistics.

\section{REFERENCES}

Ahamed, N., Rao, G, K., Murthy, R., 2000. GIS-based fuzzy membership model for crop-land suitability analysis. Agricultural Systems 63, 75-95.

Amiri, F., Shariff, M, A., 2012. Application of geographic information systems in landuse suitability evaluation for beekeeping: A case study of Vahregan watershed (Iran). African Journal of Agricultural Research Vol. 7(1), 89-97.

Arentze, T. A., Timmermans, H. J. P., 2000. ALBATROSS: A Learning-based Transportation Oriented Simulation System. EIRASS, Eindhoven University of Technology, The Netherlands.
Chen, Y., Yua, J., Khan, S., 2010. Spatial sensitivity analysis of multi-criteria weights in GIS-based land suitability evaluation. Environmental Modelling \& Software 25, 1582-1591.

Collins M, G., Steiner, F, R., Rushman, M, J., (2001). Land-use suitability analysis in the United States: historical development and promising technological achievements. Environ. Manage., 28(5): 611-621.

FAO, 1976. A framework for land evaluation. Publication Division, Food and Agriculture Organization of the United Nations, Rome.

Jafari, S., Zaredar, N., 2010. Land suitability analysis using multi attribute decision making approach. Int. J. Environ. Sci. Devlop. 1, 5.

Joerin, F., Theriault, M., Musy, A., 2001. Using GIS and outranking multi-criteria analysis for land-use suitability assessment. Int. J. Geogr. Inform. Sci. 15 (2), 153-174.

Malczewski, J., 2004. GIS-based land-use suitability analysis: a critical overview. Prog Plann., 62: 3-65.

Maris, N., Mansor, S., Shafri, H., 2008. Apicultural Site Zonation Using GIS and Multi-Criteria Decision Analysis. Pertanika J. Trop. Agric. Sci. 31(2), 147 - 162.

Oldroyd, P, B., Nanork, P., 2009. Conservation of Asian honeybees- Apidologie Bee Conservation. 40, 296-312.

Saaty, T. L. (1977). A scaling method for priorities in hierarchical structures. Journal of Mathematical Psychology, $15,234-281$.

Saaty, T. L., 1980. The analytical hierarchy process. New York: Wiley.

Saaty, T. L., 1994. Fundamentals of Decision Making and Priority Theory With The Analytical Hierarchy Process, RWS Publ. Pittsburg, 69-84.

Saaty, T, L., Decision Making with Dependence and Feedback: The Analytic Network Process, 2nd edition, PRWS Publications, Pittsburgh PA, 2001.

Saaty, T.L., Vargas, L.G., 1991. Prediction, Projection and Forecasting. Kluwer Academic Publishers, Dordrecht, 251 pp.

Wang, F., Hall, G.B., Subaryono, 1990. Fuzzy information representation and processing in conventional GIS software: data base design and applications. Int. J. Geogr. Inform. Syst. 4 (3), 261-283.

Yu, J., Chen, Y., Wu, J., Khan, S., 2011. Cellular automatabased spatial multi-criteria land suitability simulation for irrigated agriculture. Int. J. Geogr. Inform. Sci. 25 (1), 131148.

Zhang, J., Su, Y., Wu, J., Liang, H., 2015. GIS based land suitability assessment for tobacco production using AHP and fuzzy set in Shandong province of China. Computers and Electronics in Agriculture 114, 202-211.

Zolekar, R, B., Bhagat, V, S., 2015. Multi-criteria land suitability analysis for agriculture in hilly zone: Remote sensing and GIS approach. Computers and Electronics in Agriculture, 118, 300-321. 